\title{
Tank Cleaning Process dalam Menunjang Kelancaran Pemuatan Jet A-1 di Kapal Mt. Andhika Vidyanata
}

\author{
Widar Bayu Wantoro ${ }^{1)}$, Fafa Baskoro ${ }^{2)}$ \\ ${ }^{1,2)}$ Politeknik Maritim Negeri Indonesia \\ Jl. Pawiyatan Luhur 1/1, Bendan Duwur, Gajah Mungkur, Kota Semarang, Jawa tengah, 50233 \\ Email: bayu@polimarin.ac.id
}

\begin{abstract}
Abstrak
Persiapan ruang muat yang baik merupakan salah satu faktor penting dalam proses kegiatan bongkar muat di kapal tanker. Tangki untuk ruang muat yang tidak siap akan mengakibatkan terjadinya kerugian bagi perusahaan, untuk itu diperlukan kerjasama yang erat antara pihak perusahaan. Penelitian ini dilaksanakan untuk mengetahui faktor-faktor yang menyebabkan kurang optimalnya pelaksanaan tank cleaning di atas kapal MT. Andhika Vidyanata. Teknik pengumpulan data yang digunakan adalah teknik observasi. Teknik pengolahan data yang digunakan dalam Penelitian ini yaitu proses editing dan metode analisa data berupa deskriptif kualitatif. Temuan masalah yang didapat dari penelitian adalah kurang optimalnya pelaksanaan kegiatan tank cleaning di atas kapal MT. Andhika Vidyanata. Kurangnya koordinasi, pengawasan, komunikasi dan juga perawatan peralatan kebersihan ruang muat merupakan penyebab proses pembersihan tangki tidak ber jalan optimal. Upaya yang harus dilakukan untuk mengatasi proses pembersihan ruang muat agar berjalan dengan optimal yaitu meningkatkan koordinasi crew kapal serta melakukan perawatan rutin terhadap alat-alat penunjang kebersihan ruang muat. Hasil yang diperoleh dari penelitian ini adalah mengoptimalkan pelaksanaan tank cleaning guna mencegah keterlambatan pemuatan di atas kapal.
\end{abstract}

Kata Kunci: tangki muatan, pencucian tangki, kapal tanker, ruang muat

\begin{abstract}
Proper loading space preparation is an important factor in the loading and unloading activities of a tanker. An unprepared tank for loading space will result in losses for the company, for that it requires close cooperation between the company. This research was conducted to determine the factors that cause the less optimal implementation of tank cleaning on the ship MT. Andhika Vidyanata. The data collection technique used was the observation technique. The data processing technique used in this research is the editing process and the data analysis method is descriptive qualitative. The problem finding obtained from the research is that the implementation of tank cleaning activities on the ship MT. Andhika Vidyanata. is not optimal. Lack of coordination, supervision, communication and maintenance of cleaning equipment for loading rooms is the cause of the tank cleaning process not running optimally. Efforts that must be made to overcome the cleaning process for loading spaces in order to run optimally are to improve ship crew coordination and carry out routine maintenance of supporting equipment for cleanliness of cargo spaces. The results obtained from this study are to optimize the implementation of tank cleaning in order to prevent delays in loading on board.
\end{abstract}

Key words: Cargo Tanks, Tank Washes, Tankers, Cargo Shelf 


\section{PENDAHULUAN}

Muatan avtur ini merupakan salah satu jenis bahan bakar penerbangan yang dirancang untuk digunakan pada pesawat terbang yang bermesin turbin gas yang berwarna cerah sampai kekuningan. Bahan bakar yang paling umum adalah jet $A-1$ yang diproduksi dengan perlengkapan spesifikasi yang sudah standar secara internasional. Sarana transportasi yang dibutuhkan untuk menggangkut muatan avtur ini adalah jenis kapal tanker khusus yang memuat berbagai macam jenis oil product yang harus memperhatikan prosedur operasi standar. Prosedur pembersihan tanki (tank cleaning procedure), prosedur muat (loading procedure), prosedur pengontrolan temperatur (temperature control procedure), dan prosedur bongkar (discharging procedure). Dalam kegiatan bongkar muat pada kapal tanker yang mengangkut product oil dimana muatan sering berganti jenis seperti premium, kerosene, solar, avtur, dan lain-lain. Pekerjaan yang tidak dapat dipisahkan dari proses tersebut adalah kegiatan tank cleaning. Waktu dan cara pelaksanaannya harus dilakukan secara efektif dan efisien. Mengingat bahwa kapal tanker yang membawa minyak putih atau minyak yang tidak berwarna terkadang berlayar dengan jarak yang sangat dekat. Sedangkan kapal harus memuat lagi dengan muatan yang berbeda, maka harus dilakukan tank cleaning secepatnya, begitu juga dalam pemuatan jet $A-1$ yang sangat sensitif terhadap kebersihan didalam tangki itu sendiri. Karena sebelum proses pemuatan, tangki muatan harus bersih dan tidak boleh ada sisa kotoran atau partikel garam yang tertinggal.

Pelaksanaan tank cleaning tersebut sering terjadi keterlambatan yang dikarenakan cara pengerjaan tank cleaning tersebut yang kurang efisien. Hal ini menyebabkan tertundanya kegiatan pemuatan di atas kapal yang mengakibatkan terjadi klaim oleh pihak penyewa. Kadang - kadang pembersihan tangki tidak selalu lancar untuk mendapatkan dry and clean certificate. Gagalnya membersihkan tangki muatan tersebut dapat mengakibatkan tertundanya pemuatan, keterlambatan kedatangan kapal di pelabuhan berikutnya dan kerugian bagi pihak perusahaan pelayaran. Keberhasilan pembersihan tangki muatan tidak hanya tergantung pada jenis bahan tangki namun juga harus memperhatikan jenis dan sifat dari muatan yang diangkut serta pengetahuan para perwira kapal dan ABK dalam pelaksanaan pembersihan tangki. Sesuai dengan sifat dan keadaan suatu muatan oil product, kemurnian dan kualitas harus tetap terjaga dikarenakan mudahnya muatan ini bereaksi terhadap zat asing dan mudah mengalami kerusakan, maka kualitasnya harus tetap dijaga. Kemurnian dan kualitas yang dimaksut adalah zat-zat atau komposisi suatu muatan oil product tidak ada yang berubah. Apabila muatan mengalami kerusakan maka pihak dari pemilik muatan (consignee) akan mengajukan klaim atau tuntutan kepada pihak kapal yang dikarenakan muatannya telah mengalami kerusakan. Kerusakan muatan pada saat pemuatan biasanya terjadi karena tangki muatan kurang bersih sebagai akibat dari proses tank cleaning yang kurang sempurna.

Pelaksanaan tank cleaning yang berhasil akan mendapatkan sertifikat kering dan bersih (dry and clean sertificate). Akan tetapi apabila dalam pembersihan tangki muatan kurang bersih maka kapal akan diperintahkan melakukan pembersihan tangki tambahan dan proses pemuatan akan tertunda serta mengakibatkan keterlambatan operasi kapal. Bila hal ini terjadi maka kapal tidak bisa memperoleh sertifikat kering dan bersih (dry and clean certificate) dari cargo surveyor. Keterlambatan pemuatan yang disebabkan oleh tangki-tangki ruang muat dalam keadaan tidak bersih sangat merugikan. Hal ini dapat terjadi disebabkan karena kurangnya peralatan pendukung yang digunakan untuk pelaksanaan tank cleaning, sehingga mengakibatkan proses pelaksanaannya memerlukan waktu yang cukup lama dan juga karena sumber daya manusia yang kurang memiliki pengetahuan atau kurang paham dalam hal proses pelaksanaan tank cleaning. Hal tersebutlah yang mengakibatkan proses pemuatan di atas kapal MT. Andhika Vidyanata menjadi terhambat. Untuk mencegah hal tersebut maka diperlukan kerjasama yang erat antara pihak perusahaan dan pihak kapal sendiri, dimana para pelaksana tank cleaning harus selalu meningkatkan kemampuan. Sementara pihak perusahaan selaku pengelola kapal harus selalu menyediakan kebutuhan alat dan bahan yang diperlukan untuk pelaksanaan tank cleaning agar dapat berjalan lancar sesuai dengan yang diharapkan. Penelitian ini diharapkan dapat memberikan sumbangsih ilmu pengetahuan dalam kegiatan tank cleaning di kapal tanker. Upaya pemanfaatan alat bantu tank cleaning secara maksimal diharapkan dapat memberikan dampak positif dalam mempersiapkan ruang muat. Pelaksanaan tank cleaning yang baik harus memenuhi standar operasional prosedur yang disajikan pada tabel.1.

Tabel.1. Aktifitas Standar Tank Cleaning

\begin{tabular}{ll}
\hline \multicolumn{1}{c}{ Aktifitas Tank Cleaning } & \multicolumn{1}{c}{ Nilai standar } \\
\hline Gas-Freeing for Cargo Tank entry & O2 Content not less than 21\% \\
& Hydrocarbon less than 1\% of LFL \\
\hline Gas-Freeing or Purging for the & Hydrocarbon decreses under less than \\
Reception of Cargo & 40\% of LFL \\
\hline Non Flammable Atmosphere & All tank non flammable condition \\
\hline Tank Cleanliness & Dry, No Residu \\
\hline & (ISGOTT, 1996)
\end{tabular}




\section{METODE PENELITIAN}

Metode penelitian ini menggunakan metode deskriptif kualitatif. Pengertian dari penelitian deskriptif yaitu sebuah metode yang memiliki fungsi untuk menemukan pandangan yang sangat luas terhadap suatu objek penelitian pada suatu waktu tertentu(Surjaweni, 2014). Penelitian kualitatif diartikan sebagai penelitian dimana peneliti ditempatkan sebagai instrument kunci. Sedangkan untuk pengumpulan datanya dilakukan dengan cara penggabungan dan analisis data yang bersifat induktif(Sugiyono, 2017). Penelitian ini dilakukan di atas kapal tanker yang biasa digunakan untuk memuat white oil atau oil product dari hasil pengilangan minyak bumi. Kapal biasa digunakan untuk mengangkut muatan yang berbedabeda jenisnya. Sasaran ilmiah pada kapal tanker untuk mendapatkan data tujuan serta kegunaan secara obyektif, valid, dan realibel pada variabel tertentu(Sugiyono, 2017). Penelitian dilakukan di atas kapal MT. Andhika Vidyanata yang memiliki data ship's particular pada Tabel.2. Obyek penelitian lebih spesifik terdiri dari alat bantu tank cleaning, proses pekerjaa dan awak kapal yang terlibat langsung pada tank cleaning operation.

Tabel 1. Ship's Particular

\begin{tabular}{ll}
\hline Ship Name & MT. ANDHIKA VIDYANATA \\
\hline Owner & PT. ANDYANA \\
\hline Class/Class No & ABS/ABS+A1 ESO OIL CARRIER + AMS WILD RRDA \\
\hline IMO Number & 9823417 \\
\hline Registry/Flag & Jakarta/Indonesia \\
\hline Call Sign & Y C G X 2 \\
\hline MMSI Number & 525106001 \\
\hline GRT/NRT & $5488 \mathrm{mts} / 1829 \mathrm{mts}$ \\
\hline LOA & $108.0 \mathrm{~m}$ \\
\hline DWT & $6,969.38$ tonnes \\
\hline Main Engine & HANSIN / 2194 HP $(2942 \mathrm{KW})$ \\
\hline
\end{tabular}

(Ship's Particular, 2019)

Obyek penelitian sebagai pusat perhatian dijadikan sasaran utama dalam pengumpulan data. Metode pengumpulan data merupakan suatu bagian yang penting dalam penelitian. Untuk mendapatkan suatu data yang relevan dengan pokok permasalahan maka peneliti menggunakan teknik pengumpulan data yang tepat. Teknik pengumpulan data merupakan cara mengumpulkan data yang dibutuhkan untuk menjawab rumusan masalah penelitian. Ada beberapa metode yang digunakan untuk mengumpulkan data, diantaranya dengan menggunakan teknik wawancara, pengamatan (observation), angket (questioner), dan studi dokumentasi (Sugiyono, 2017).

Metode yang digunakan untuk pengumpulan data pada penulisan didasarkan pada suatu data, fakta dan informasi yang didapat oleh peneliti langsung dari kapal. kemudian dari data observasi dan informasi data yang ada tersebut menjadi bahan acuan dalam melakukan penulisan. Informasi lain yang diperoleh dari Mualim dan Nakhoda merupakan sumber data langsung yang nyata dari pengalaman.Observasi merupakan salah satu teknik penelitian yang dilakukan melalui pencatatan secara sistematik dengan mengamati gejala- gejala yang diteliti (Surjaweni, 2014). Pencatatan secara dilakukan sistematik terhadap gejala yang tampak pada objek penelitian. Peneliti mengamati dan melihat kemudian mencatat secara langsung pelaksanaan kerja, aktivitas serta masalah yang terjadi untuk memperoleh gambaran yang otentik dan akurat. Observasi akan menjadi terarah apabila mengikuti pedoman sebagai acuan dalam pengumpulan data. Proses observasi pada kegiatan tank cleaning dilakukan dengan berdasarkan dengan standar operasional prosedur dan keselamatan.

Interview dilakukan sebagai percakapan yang memiliki tujuan tertentu. Perbincangan dilakukan ole dua belah pihak, yaitu sang pewawancara yang mengajukan beberapa pertanyaan dan orang yang diwawancarai memeberikan respon atau jawaban atas pertanyaan yang diajukan. Metode wawancara yang digunakan peneliti yaitu wawancara yang tidak terstruktur dimana pengertian wawancara tidak terstruktur adalah pewawancara bebas menanyakan apapun tanpa ada pedoman wawancara yang sudah tersusun secara sistematis, melainkan hanya garis-garis besar dari suatu permasalahan yang ada untuk mengumpulkan datanya. Dengan metode ini peneliti mencoba memperoleh data melalui wawancara langsung dengan Chief Officer kapal MT. Andhika Vidyanata sebagai penanggung jawan cargo operation and tank cleaning operation. Dokumentasi juga dilakukan untuk mencari data mengenai hal-hal atau variabel yang berupa catatan, transkip, buku, majalah, soft file, hardfile, foto dan data lainnya. Data-data tersebut merupakan data yang konkrit dan dapat memberikan keterangan nyata yang benar-benar terjadi diatas kapal, data- data tersebut juga telah didokumentasikan dan dilaporkan kepada perusahaan. Setiap kapal terdapat dokumen yang berkaitan dengan kapal dan dianjungan kapal terdapat dokumen tersendiri mengenai cara dan proses pelaksanaan tank cleaning diatas kapal. Dokumen-dokumen mengenai tank cleaning antara lain di buku ISGOTT dan tanker vessel procedure. 


\section{HASIL DAN PEMBAHASAN}

\subsection{Temuan Masalah}

1) Ketika penulis sedang melakukan pengamatan, penulis menemukan masalah ketika tank cleaning yaitu Wilden Pump yang digunakan untuk tank cleaning terjadi kemacetan sehingga menunggu perbaikan yang cukup lama. Secara otomatis wilden pump harus di bongkar agar mengetahui penyebab kemacetan tersebut. Berhubung waktu pelayaran yang cukup singkat, sehingga waktu proses tank cleaning menjadi terpotong yang mana proses tank cleaning menjadi terhambat. Anak buah kapal tidak menyadari betapa pentingnya alat tersebut dalam proses pembersihan tangki. Anak buah kapal sering mengabaikan pekerjaan ini, mereka lebih mementingkan pekerjaan di deck dari pada perawatan alat-alat tank cleaning.

2) Proses tank cleaning merupakan bagian penting dan sangat menentukan dalam proses pengoperasian oil product tanker oleh perusahaan pelayaran. Pada saat kapal selesai melaksanakan kegiatan bongkar di pelabuhan Makassar, kapal MT. Andhika Vidyanata diperintahkan memuat di pelabungan Tanjung Manggis. setibanya di pelabuhan muat kapal MT. Andhika Vidyanata diperintahkan untuk langsung sandar dikarenakan pelabuhan Benoa sangat membutuhkan supply avtur (Jet A-1). Akan tetapi setelah kapal sandar ternyata kapal dinyatakan belum siap muat oleh Loading Master dan Surveyor Indonesia di karenakan pada tangki kapal masih terdapat serpihan karat dan sedikit genangan muatan di daerah bellmouth. Dikarenakan tangki belum siap untuk dimuat maka pihak Loading Master dan Surveyor Indonesia memerintahkan kapal untuk membersihkan kembali hingga tangki siap untuk dimuat dan kapal tidak bisa mendapatkan sertifikat kering dan bersih (dry and clean certificate) sebelum tangki muat benarbenar bersih dan kering. Dengan kejadian tersebut maka proses pemuatan menjadi terhambat.

\subsection{Pembahasan Masalah}

Berdasarkan temuan masalah yang terkait rumusan masalah pertama, maka dapat dianalisa bagaimana peranan alat bantu tank cleaning dalam kelancaran prosess tank cleaning. Peranan alat bantu tank cleaning dalam pelaksanaan proses tank cleaning di kapal MT. Andhika Vidyanata sebagai berikut:

1) Peranan alat bantu tank cleaning seperti wildenpump, hose dan freegases fan dalam pelaksanaan tank cleaning bisa di katakan sangat vital(Robert, 2003), karena jika alat-alat tersebut rusak maka pelaksanaan tank cleaning akan terhambat. Peranan alat bantu tank cleaning sangat berpengaruh terhadap nilai kepuasan pihak PT. Pertamina Persero ketika melaksanakan pengecekan tangki karena apabila pada pelaksanaan tank cleaning ditunjang dengan alat bantu yang layak dan juga memadai, maka proses dari pembersihan tangki akan berjalan dengan optimal dan maksimal serta menghasilkan tangki yang bersih dan sesuai standar dari pihak PT. Pertamina Persero.

2) Keterbatasan jumlah wilden pump dan freegases fan serta hose menjadi hal yang sangat vital yang membuat peranan alat-alat bantu tersebut menjadi tidak maksimal. Peralatan yang digunakan untuk tank cleaning yang ada di atas kapal MT. Andhika Vidyanata adalah selang (hose), blower (portable freegases fan) serta wilden pump. Karena keterbatasan alat-alat bantu ini, untuk proses pencucian dari tangki satu ke tangki yang lain akan memakan waktu yang cukup lama yang mana dapat mengakibatkan tangki belum siap untuk dimuati. Untuk jumlah alat bantu tank cleaning diatas kapal yaitu satu buah wilden pump dan dua buah freegases fan. Pada saat terjadi kerusakan pada butterworth, wilden pump, atau portable fan maka secara otomatis kegiatan tank cleaning akan berhenti karena harus menunggu perbaikan. Selain itu setelah melaksanakan proses tank cleaning alat tersebut tidak langsung dibersihkan dengan air tawar dan tidak diberi oli/minyak pelumas.

3) Peranan alat bantu tank cleaning menjadi kurang maksimal karena suku cadang yang tidak tersedia di kapal. Semua peralatan yang ada di atas kapal termasuk alat- alat bantu tank cleaning harus dipastikan memiliki spare part atau suku cadang yang dapat digunakan sewaktu-waktu jika ada alat yang mengalami kerusakan dan dibutuhkan perbaikan serta penggantian spare part pada bagian alat tersebut. Dalam manajemen kontrol spare part sangat penting dilaksanakan pengecekan rutin oleh chief officer dan bosun sebagai orang yang bertanggung jawab atas kegiatan tank cleaning di atas kapal(Ansori. N, 2013).

4) Pelaksanaan jadwal perawatan alat bantu tank cleaning yang teratur membuat peranan alat bantu tank cleaning dapat berjalan maksimal. Proses pelaksanaan perawatan dan pemeliharaan alat bantu tank cleaning dalam kerja ratings harian ataupun perawatan bulanan harus sesuai dengan manual book. Pelaksanaan perawatan yang tidak tepat waktu akan membuat semakin cepat alat- alat tersebut berkarat dan rusak.

Berdasarkan temuan masalah yang terkait rumusan masalah kedua, maka dapat dianalisa faktor faktor yang mempengaruhi ketidaklancaran tank cleaning. Faktor-faktor yang mempengerahui ketidaklancaran tankk cleaning antara lain:

1) Proses awal sebuah kapal tanker dalam melaksanakan operasional atau kegiatan memuat adalah persiapan ruang muat dengan tank cleaning. Persiapan ini sangat penting dan harus banar-benar diperhatikan terutama muatan yang berlainan jenis atau muatan yang sensitif dan muatan yang peka tarhadap zat lainnya sehingga akan mudah rusak, contohnya adalah muatan avtur yang digunakan sebagai bahan bakar untuk pesawat terbang. Kebersihan dan warnanya 
pun harus di jaga sedemikian rupa agar muatan tersebut tidak rusak. Terutama zat cair avtur langsung rusak apabila terkena atau bercampur dengan air, maka kadarnya akan berubah. Dalam pelaksanaan persiapan tangki diperlukan seorang yang profesional dan tahu seluk beluk kapal tempatnya bekerja, serta didukung oleh anak buahnya yang terampil sehingga mampu menyiapkan ruang muat dengan baik. Tetapi pada praktenya untuk keterampilan dari anak buah kapal bisa dibilang kurang karena ada dua juru mudi baru bekerja 3 minggu diatas kapal yang mana juru mudi tersebut sebelumnya bekerja di kapal curah dan juga kapal tanker jenis crude oil yang jarang sekali melakukan tank cleaning.

2) Dalam proses tank cleaning diperlukan waktu yang cukup agar proses tank cleaning yang dikerjakan mendapatkan hasil yang baik dan maksimal. Akan tetapi apa yang diharapkan itu tidaklah tercapai dikarenakan route pelayaran yang cukup singkat yaitu sekitar 33 jam dari pelabuhan bongkar ke pelabuhan dimana kapal akan memuat. Dengan jumlah 10 buah tangki yang direncanakan akan dimuat avtur, maka proses pembersihan untuk 1 tangki saja membutuhkan waktu sekitar 4 jam agar tangki benar-benar bersih dan mendapatkan hasil yang baik. Jadi untuk membersihkan 10 tangki yang ada dibutuhkan waktu normal sekitar 40 jam, sedangkan waktu pelayaran hanya 33 jam. Maka waktu yang ada sangatlah kurang untuk melaksanakan proses pembersihan tangki.

3) Ketika pelaksanaan tank cleaning diatas kapal terdapat prosesdur tank cleaning yang harus dilaksanakan. Tetapi dalam prakteknya masih ada beberapa crew yang kurang disiplin dalam menjalakan prosedur tank cleaning seperti tidak memakai safety helm dan respirator. Hal ini akan mengakibatkan terjadinya kecelakan kerja yang mana akan berhujung menghambat proses pelaksanaan tank cleaning. Serta masih ada crew kapal yang tidak membersihkan seluruh tangki muat, melainkan hanya bagian-bagian yang terlihat saja.

Tujuan dari persiapan ruang muat yaitu untuk menunjang kelancaran proses pemuatan dan operasional kapal. Namun pada pelaksanaannya banyak ditemukan masalah-masalah yang mengakibatkan terhambatnya pelaksanaan pemuatan maupun pembongkaran. Oleh karena itu timbul perhatian untuk mencari penyelesaiannya guna mengatasi hambatanhambatan yang akan terjadi. Dalam hal ini penulis mengambil alternatif pemecahan masalah adalah sebagai berikut:

1) Untuk mengoptimalkan proses persiapan ruang muat dan pencucian tangki, perlu diadakan pertemuan rutin (safety meeting) sebelum melaksankan pembersihan ruang muat yang dipimpin oleh mualim I. Dalam setiap pertemuan dipaparkan dan dibahas tahapan-tahapan dan prosedur kerja. Tugas dan tanggung jawab masing-masing kelompok kerja serta peralatan-peralatan yang diperlukan dalam pelaksanaan persiapan tangki muat agar dapat dicapai sebuah tema work yang padu untuk mencapai hasil yang maksimal(International Maritime Organization (IMO), 1990).

2) Untuk meningkatkan pengetahuan dan keterampilan Anak Buah Kapal (ABK) tentang bongkar muat, maka perlu mengadakan familiarisasi dan serah terima antara crew yang baru dan crew yang lama sesuai situasi yang sebenarnya. Perusahaan harus memberikan pendidikan atau pengetahuan singkat mengenai prosedur bongkar muat sebelum Anak Buah Kapal (ABK) dinaikkan ke kapal dan perusahaan harus menyeleksi Anak Buah Kapal (ABK) secara selektif sebelum diterima dan ditempatkan di atas kapal. Proses penyeleksian yang baik akan sangat bermanfaat untuk mendapatkan tenaga kerja yang terampil karena dengan semakin tinggi kualifikasi, maka akan berdampak positif dalam keberhasilan pekerjaan tersebut. Untuk meningkatkan kedisiplinan Anak Buah Kapal (ABK) dalam persiapan tangki muat maka diharapkan agar mualim I sebagai penanggung jawab atas muatan selalu melakukan pengawasan dalam pelaksanaan tank cleaning. Karena pekerjaan ini dikerjakan berdasarkan kelompok kerja atau tim, dimana suatu kelompok terdiri atas empat orang yang saling bekerja sama untuk menghasilkan suatu pekerjaan yang maksimal maka peran Mualim I sangatlah penting untuk membuat suasana kerja yang nyaman. Mualim I haruslah mengawasi dan turun langsung ke lapangan untuk melihat hasil kerja dari bosun, juru mudi, os dan kadet. Karena dalam pelaksanaan tank cleaning, seorang Mualim kadang hanya melihat tangki yang sudah kering dan bersih dari atas lubang tangki (Tank dome) saja tanpa turun langsung kedalam tangki untuk melakukan pengecekan, oleh karena itulah sering ditemukan sisa- sisa cargo/air pada bak isap muatan (Belmouth) di dalam tangki. Dalam hal ini peran dari seorang Mualim di atas kapal sangat penting untuk memeriksa sendiri dan memberikan arahan serta masukan yang baik tentang pekerjaan kepada anak buah kapal (ABK) yang melaksanakan pembersihan tangki muatan agar tidak mengalami pengulangan dalam pekerjaan.

3) Meningkatkan kordinasi yang baik antara pihak kapal dengan pihak perusahaan yaitu yang menyangkut dalam masalah waktu. Hal ini sangatlah diperlukan sekali oleh pihak kapal dengan penyesuaian waktu mulai dari tempat pemuatan ketempat pembongkaran, sampai kembali lagi ke tempat pemuatan. Harus dilakukan proses pembersihan tangki apabila muatan yang akan diangkut tidak sama dengan muatan sebelumnya. Dengan diadakannya penyesuaian waktu, maka proses tank cleaning akan dapat berjalan dengan baik dan sesuai dengan yang direncanakan.

4) Mualim I harus membuat suatu rencana kerja yang matang dan selalu memperhitungkan langkah-langkah yang akan digunakan jika nantinya terdapat kendala dalam pelaksanaan tank cleaning sehingga Mualim I bisa dengan cepat dan tanggap untuk dapat mencari jalan keluar bagi masalah yang terjadi. Mengutamakan keselamatan kerja dengan mengikuti peraturan-peraturan dan prosedur dalam pelaksanaannya adalah hal yang diharapkan oleh semua orang dimanapun tempat mereka bekerja, tetapi tidak semua orang dapat bertindak hati-hati dan tentu saja tidak ada yang 
dapat menjamin suatu kecelakaan tidak akan terjadi walaupun orang itu sudah sangat berhati-hati dalam melaksanakan pekerjaannya.

5) Perlunya perawatan terhadap alat-alat tank clening secara teratur, terutama setelah menggunakan alat tank clening harus segera diberi pulmas atau dibilas dengan air tawar. Serta peranan perusahaan untuk penambahan atau supply kebutuhan dan peralatan tank clening sangat berpengaruh dalam proses tank cleaning agar pelaksanaan tersebut berjalan dengan optimal sehingga kapal tidak terjadi keterlambatan dalam proses bongkar muat.

6) Hendaknya crew di atas kapal diberikan tontonan melalui video-video tentang tata cara pelaksanaan tank cleaning yang dilakukan dengan baik dan benar. Karena hal ini sangat berguna sekali bagi anak buah kapal (ABK) khususnya crew deck, agar dapat memberikan wawasan dan pengetahuan serta menambah keterampilan pada setiap crew dalam pelaksanaan tank cleaning di kapal, guna menunjang operasional dan ketepatan waktu dalam pengerjaannya.

\section{KESIMPULAN}

Berdasarkan hasil dari penelitian yang peneliti lakukan terhadap pelaksanaan pembersihan ruang muat pada kapal MT. Andhika Vidyanata dapat disimpulkan sebagai berikut: Peranan alat bantu tank cleaning dalam pelaksanaan pembersihan tangki bisa di katakan sangat vital, karena jika tanpa alat- alat bantu tersebut pelaksanaan tank cleaning akan terhambat. Kuantitas, kualitas serta perawatan alat bantu tank cleaning harus di perhatikan sebaik mungkin, karena hal tersebut sangat berpengaruh terhadap maksimalnya peranan alat bantu tank cleaning terhadap pelaksanaan tank cleaning di atas kapal. Peranan alat bantu tank cleaning sangat berpengaruh terhadap nilai kepuasan pihak PT. Pertamina Persero pada saat melaksanakan pengecekan tangki sebelum proses memuat muatan (avtur). Perlengkapan kebersihan ruang muat tidak mencukupi karena banyak dari peralatan penunjang kebersihan ruang muat yang sudah rusak dan tidak bisa digunakan secara maksimal untuk melaksanakan proses tank cleaning. Hal itu disebabkan karena kesadaran awak kapal yang sangat kurang untuk menjaga dan merawat peralatan penunjang kebersihan ruang muat, serta terlambatnya respons shipping order dari mualim kepada kantor perusahaan tentang permintaan alat-alat penunjang kebersihan ruang muat dan rute kapal yang sangat singkat membuat proses tank cleaning tidak berjalan dengan optimal. Hal ini mengakibatkan tangki masih terdapat kotoran dari sisa-sisa muatan sebelumnya sehingga ketika Loading Master dan surveyor melakukan pemeriksaan mereka menyatakan bahwa tangki muatan belum siap. Upaya yang di lakukan agar proses tank cleaning berjalan dengan maksimal adalah memperhatikan serta melaksanakan PMS (Plan Maintenance System) pada alat bantu tank cleaning dan pengecekan suku cadang dilaksanakan secara teratur, melaporkan secara teratur kuantitas suku cadang alat bantu tank cleaning dan melaksanakan jadwal rutin khusus perawatan alat bantu tank cleaning. Selain itu perlunya diberikan wawasan atau pengetahuan tentang proses tank cleaning sesuai prosedur, selalu berkoordinasi dengan pihak perusahaan yang berkaitan dengan waktu penyandaran serta meningkatkan pengawasan ketika pelaksanaan proses tank cleaning. Dengan begitu proses pelaksaan tank cleaning akan menjadi maksimal sehingga tidak akan terjadi keterlambatan pemuatan lagi.

\section{UCAPAN TERIMAKASIH}

Ucapan terimakasih penulis ucapkan kepada seluruh pihak yamg telah membantu proses penelitian sampai tersusunnya laporan dan menjadi artikel ilmiah. Terimakasih yang sebesar-besarnya peneliti sampaikan kepada seluruh awak kapal MT. Andhika Vidyanata

\section{DAFTAR PUSTAKA}

Ansori. N, M. M. . (2013). Sistem Perawatan Terpadu. Graha Ilmu.

International Maritime Organization (IMO). (1990). Safety Of Life At sea (Third Edit). International Maritim Organization.

ISGOTT. (1996). International Safety Guide for Oil Tanker and Terminal (4th Editio). Witherby \& Co.

Robert, P. (2003). Peralatan Tetap dan Peralatan Portable.

Ship's Particular. (2019). MT. ANDHIKA VIDYANATA.

Sugiyono. (2017). Metode Penelitian Kuantitatif, Kualitatif dan R\&D (Bandung). CV. Alfabeta.

Surjaweni, V. W. (2014). Metode Penelitian: Lengkap, Praktis, dan Mudah Dipahami. Pustaka Baru Press. 